\title{
VR Technology to the Adjustment of Piano Playing Mentality
}

\author{
Yu Zhang \\ College of Music, Shenyang Normal University, Shenyang 110034, Liaoning, China \\ Correspondence should be addressed to Yu Zhang; shenshizhangyu@synu.edu.cn
}

Received 25 June 2021; Revised 30 July 2021; Accepted 11 August 2021; Published 23 August 2021

Academic Editor: Sang-Bing Tsai

Copyright (c) $2021 \mathrm{Yu}$ Zhang. This is an open access article distributed under the Creative Commons Attribution License, which permits unrestricted use, distribution, and reproduction in any medium, provided the original work is properly cited.

\begin{abstract}
Piano performance requires not only skillful and excellent playing skills, but also good psychological quality and improvisation. The perfect performance is the natural language of a pianist's usual skill and mood. The various emotional activities and expressions of the overall situation in relation to the player's performance, mental issues such as the intensity and horror of the scene, seriously affect the pianist's actual performance while playing. The piano is therefore very important for mind control. Based on this, this paper attempts to apply the current hot VR technology to piano performance and simulate the virtual piano performance scene through VR technology, so as to enhance the on-the-spot experience for piano players and continuously improve their psychological quality, so that they can better adjust their nervous bad mentality in actual combat. This article first has carried on the 3D virtual reality piano stage modeling experiment, and then selected the 20 young pianist piano training involved in day-to-day contrast test, the test group of 10 people for daily training, virtual piano stage under the environment of normal control group of 10 people ordinary daily training, training time four hours a day, for three months, all participants will take part in The Provincial Youth Piano Competition since the end of the training. The final test results showed that in the competition site, the performance level of 10 players in the test group was generally better than that of the control group. Among them, there were 2 subjects in the test group who played for a long time, while one of the control groups gave up playing in the middle. In addition, in the horizontal comparison, it is found that subjects who are older and have been learning piano for a long time have better on-the-spot mental adjustment ability and more stable performance. Boys performed better than girls, and subjects with positive, optimistic, and confident personalities performed better than those with introverted and low selfconfidence.
\end{abstract}

\section{The Introduction}

1.1. Background and Significance. Piano playing is an elegant performing art as well as an exquisite and highly technical art. Exquisiteness embodied in the player's hands will be very important, and technicality embodied in the need for years of practice. The ultimate success of a piano concert depends not only on whether the player has excellent performance skills, but also on whether the player has a good psychological quality and mentality. In actual performance, many players are often too nervous, due to stage fright, to give full play to their normal performance level and often play wrong notes on the spot or even stop playing. Piano playing skills can be acquired through continuous self-strengthening exercises, but it is difficult to overcome the bad mentality of tension, which requires players to accumulate more experience of playing on the spot and strengthen psychological adaptability training.

Usually, most of the daily practice of pianists is only in closed and narrow spaces. This makes actors nervous about differences on stage or in the competition and mental problems such as nervousness and panic and physical discomfort such as sweating and trembling because they cannot manage and control their bad minds and emotions. Players often cannot play normally. For this reason, this paper proposes to use VR technology to assist the adjustment of piano players' mentality. VR technology, as an advanced high-tech means at present, can realize $3 \mathrm{D}$ simulation of the dynamic world. By setting up a virtual piano performance stage, players can be placed in it for performance simulation training, thereby enhancing the actual expressiveness of piano performance, assisting players in daily psychological 
adaptability training and allowing players to train without a piano. It can also simulate the situation in a concert hall, which is very practical.

1.2. Related Work. The artistic development of piano has a long history. As an elegant artistic activity, people love for it is obvious. At first, piano performances were given only by the upper class, but with the development and progress of the society, more and more people from the middle and lower classes gradually pay attention to and experience this artistic activity, and many relevant experts and scholars have even studied it. Tian Tian pointed out that performing a piano requires high technical requirements for players by having to acquire knowledge from multiple disciplines including knowledge of philosophy, biology, religion, and history, as well as an understanding of the musical background and the combination of emotion to actual performance [1]. In addition, piano players should have good psychological adjustment ability and improve the level of psychological intervention as playing skills to be competent for piano playing. In piano teaching, Bian emphasized that in order to improve the vitality and efficiency of music teaching [2], VR system has multi-induction, immersion, and interaction functions of virtual reality technology, which can solve the problems of low cross-sense and low efficiency in traditional music teaching. He proposes an online error recognition algorithm that evaluates teaching effectiveness through size and confirmatory factor analysis. Chen also points out that integrated network and multimedia applications have created a new format for modern piano teaching and performance. This model can combine traditional networking platforms and new media to develop new fields [3]. He has carried on the optimization analysis to the modern piano performance mode based on the multimedia system. In the process of playing the piano, pianists should continue to improve the relevant requirements through scientific and rigorous training. Using digital piano classroom for teaching can greatly improve the effect of piano skill training and help to optimize and improve the quality of music education. At present, most of the research studies on piano works are basically about playing skills, but there is very little research on players' attitude adjustment; many piano educators seem to ignore the psychological factors, and with the development of piano education in China. The pianist playing the emotions out of control leads to play to the phenomenon of losing more and more common; players' psychological barriers and bad mentality problem has become more and more urgent need to be resolved [4-6].

1.3. Innovation Points of This Paper. This article innovation mainly manifests in the following aspects: (1) VR technology is proposed to be applied to pianos and through a $3 \mathrm{D}$ virtual piano scene to meet the daily training of pianists to allow them to experience the feeling of a live performance, enhancing real piano experience, it also allows the performer to experience the feeling of live performance without leaving the house, enhances the player's sense of immersion, and promotes the training of their psychological endurance. (2)
Taking 20 young piano learners as the research objects, this paper compares their off-stage performance and live performance under different daily piano training methods, so as to analyze the auxiliary role of VR technology in the adjustment of piano playing mentality in a more specific and vivid way.

\section{VR Technology's Assistance to the Adjustment of Piano Performance Mentality}

\subsection{VR Technology}

2.1.1. Overview. VR stands for virtual reality. VR technology is a high-tech emerging technology, also known as "Lingjing Hutong Technology". Use computer and multimedia technology to display real-world images with dynamic 3D effects in the virtual world. The world born of the virtual world is the crystallization of the rapid development of computer technology, software and hardware, robots, and sensor technology. Artificial intelligence technology and computer technology include network technology, communication technology, and remote sensing technology [7, 8]. Flight simulators were designed in the US in the 1940s, a computer screen was proposed in 1965 as a window into a virtual world, and the real concept of virtual reality emerged in the 1980s. Since then, with the continuous deepening of people's research and the development of computer science and technology, VR technology has become mature and widely applied in various fields of society.

2.1.2. Features of VR Technology. VR is considered the highest level of multimedia application. It combines computer technology, optical physics, optical psychology, simulation technology [9], sensor technology, voice recognition, artificial intelligence, and other high-tech methods and interact with them to achieve the integration of various hightech technologies [10-12]. It is a combination of emerging high-tech technologies in modern society. The 3D dynamic world constructed by VR technology has extremely strong fidelity and real-time performance, which has the following specific characteristics [13].

Immersion: VR technology simulates the real world with extremely high sense of reality and lifelike. Users can fully immerse themselves in the virtual environment by wearing $3 \mathrm{D}$ glasses and other tools to achieve the effect of indistinguishable from the real world, giving users a sense of onthe-spot experience [14-16]. In the three-dimensional virtual environment built by VR technology, everything seems to be real. What you see, hear, touch, smell, and even taste are all real, just like what you feel in the real world [17].

Real-time interaction: Interactivity refers to the user in a virtual environment; the objects the user touches or catches are tactile and can feel the weight, and the objects can move along with the movement of human hands, with strong operability [18].

Conceptualization: In the three-dimensional dynamic space, users can obtain any virtual information in the space according to their own perception and judgment $[19,20]$. 
They can give full play to their subjective initiative and seek for the knowledge and information they need to cope with and solve problems perfectly.

2.1.3. The Core of VR Technology. VR technology involves the application of technologies in many fields, including dynamic modeling, three-dimensional image formation, and information sensing. The details are given below.

3D dynamic modeling technology: To build a 3D virtual environment, first of all, a dynamic model should be established. The 3D data can be obtained by scanning the actual objects and environment, and then a virtual environment model can be established by using the acquired 3D data [21]. 3D data can be obtained through CAD technology, but due to the abstract nature of the environment, the noncontact means of laser scanning confocal microscope is more often used to obtain the $3 \mathrm{D}$ data of the environment and complete the dynamic visual modeling.

3D image generation technology: After the dynamic modeling of virtual environment is completed, it is necessary to generate the virtual reality image of the built model. It requires $3 \mathrm{D}$ image refresh rate of virtual world not less than 15 frames/s, preferably more than 30 frames/s [22, 23]. Under the premise of not reducing image quality and content, maximum improvement of refresh rate is the key point to be studied in 3D image generation technology [24].

Sensor and 3D display technology: The reason why 3D virtual world can bring high sense of reality and presence to users lies in its powerful real-time interaction, which is realized through sensor technology and 3D display technology. As long as users make signals through tools such as data gloves or $3 \mathrm{D}$ glasses, the $3 \mathrm{D}$ virtual space will get information by virtue of its sensing system and make corresponding responses quickly $[25,26]$.

System integration technology: Because the $3 \mathrm{D}$ virtual world contains a lot of data and models, the integration technology of the system is very important to improve the spatial response speed. Integration technology solves the synchronization of spatial data information, model calibration, data transformation and data management, identification and synthesis.

This article explains the characteristics of the technique in each musical period and the performance technique.

$$
E_{c}=\frac{1}{L} \sqrt{\sum_{i=0}^{l-1}\left[Y(K-i)-Y_{m}(K-i)\right]^{2}} .
$$

Here, $L$ is the evaluation time zone.

$$
C[i]_{d}=C[i]+\frac{C[i+1]_{m}}{f_{m}^{\max }-f_{m}^{\min }} .
$$

Here, Crowd $[i]_{d}$ represents the sound coefficient.

$$
\min \left(E^{2}\right)=\sum_{k=1}^{N}\left[Y^{\prime}(K)-Y(K)\right]^{2} .
$$

Among them, $y(k)$ is the measured value and $N$ is the number of data points.

$$
\operatorname{Angle}(A, R)=\arccos \left(\frac{A \bullet R}{|A| *|R|}\right) \text {. }
$$

The vector $a$ is obtained by connecting.

Application system development tools: The establishment of three-dimensional virtual space is based on the real environment and objects. In order to establish a virtual reality world, we must first find a suitable place and object, and give play to our imagination and creativity. However, this process is too complex and takes a long time, which is not conducive to the improvement of production efficiency and product development quality. Therefore, it is necessary to study the development tool of virtual reality and realize the autonomous target positioning of real occasions and objects through this tool. In this way, the production efficiency of products will be greatly improved.

$$
\begin{aligned}
W & =\exp \left(\frac{\chi_{i} D_{\mathrm{HOL}, i}-x}{1+\sqrt{x}}\right), \\
Y & =\sum_{1}^{N} \phi_{i} D_{\mathrm{HOL}, i}, \\
P_{w}\left(s, s^{\prime}\right) & =P\left(s, s^{\prime}\right)\left(A_{1}=A_{2}\right) .
\end{aligned}
$$

$W_{i j}$ represents the final delay power.

2.1.4. Application of VR Technology. With the rapid development of science and technology, VR technology is becoming more and more common around us, and its application fields are more and more extensive.

Common applications of VR technology include the following:

Film and television games and other entertainment fields: Traditional film and television games are only viewed, appreciated, or experienced unilaterally by users on one end of the TV or computer, while film and television games that apply VR technology can achieve two-way interaction between man and machine. The user can enjoy the three-dimensional effect of the game in the virtual reality world, which can greatly satisfy the user's sense of participation experience and immersion.

In the performance, the probability of using the middle pedal is also very small, but it gives the composition more expressive power. Its use can make the phrase more coherent, highlight the heaviness brought by the continuous bass to the music, and highlight the contrast of the musical levels. In each music period, the development of piano techniques is also changing.

$$
\phi_{f}=L_{i} \times\left(R_{i+1} \tau_{f}\right)+\left(L_{i}+b_{i}\right) \times F_{i}+N_{i}
$$

Among them, $\phi$ is the image pixel obtained by cutting. It is an indispensable auxiliary tool for the performer in the perfect interpretation of the composition. 


$$
\delta_{B}(k)=U_{1} K-\left[\frac{U_{3}(K-1)}{U_{3}(k)}\right] \times U_{1}(k) .
$$

$\delta_{B}(k)$ is the separation index.

Military space: VR technology can help the simulation training of military space, whether it is military exercises or space station environment simulation; it can be achieved through VR technology.

The field of medicine: The application of virtual reality technology in medicine is mainly integrated with the study of anatomy, pathology, and surgery. In teaching, virtual human models are created through VR technology with the help of gloves, sensors, and tracking balls. Students can understand the structure of organs of the human body easily. This is more convenient than using textbooks alone for teaching and students understand faster. At the same time, students can also use virtual laboratory for autopsy and surgery training practice, before the operation, the surgeon can use VR technology to simulate the operation repeatedly on the computer monitor, complete the design of the complex operation, and find the best operation plan, which can greatly reduce the operation risk.

The field of culture and art: VR technology can dynamically present static art forms, such as paintings and sculptures, and establish dynamic models through scanning three-dimensional data, so as to complete the dynamic presentation. In this way, it broadens the channels and forms for people to understand art and makes it more convenient for people to learn.

Heritage and protection of cultural relics and historic sites: VR technology is conducive to the inheritance and protection of cultural relics and historic sites. After inspection and verification, it is determined that the revised content is consistent with the original intention of the author. At the same time, the display of cultural relics and historic sites in virtual reality does not need to worry about or consider geographical restrictions, so as to realize resource sharing to the greatest extent. In addition, since people visit cultural relics and historic sites through the virtual reality world, they do not need to have direct contact with cultural relics, so they can effectively protect cultural relics and historic sites from the influence of excessive tourists.

The field of production: The most obvious application of VR technology in the field of production is the virtual development of cars. By wearing $3 \mathrm{D}$ glasses and sitting in the car, users can simulate the feeling of operating the car on the real road. In addition, in the process of designing and producing the car, designers can also analyze the shortcomings of the car in a timely and efficient manner and make improvements, thus effectively saving the production cost of the car.

2.2. Attitude of Piano Performance. Piano is a kind of keyboard instrument in western classical music. It has the title of "the King of Musical Instruments". It consists of 88 keys and metal strings. Piano performance requires a great deal of skill, and the players need to strengthen the practice and training in order to develop more skilled and exquisite playing skills. A successful piano performance needs players not only with excellent performing skill, but also the natural language of the true feelings, but in the process of actual performance, although many players have strong performance skills, they are prone to nervousness, stage fright and other bad emotions during performances, and they are unable to express their true emotions in the performance, which makes it difficult for them to perform at a normal level of performance.

After the reform and opening up, with the deepening of cultural exchanges between China and the West and the improvement and improvement of the living standards of the Chinese people, the number of people studying piano in China has also increased. After Langlang and other domestic pianists have gained a reputation in the world, piano learning in China has reached a new level. Many parents send their children to school at a young age. The basic skills of the younger generation are very stable and more and more people take part in piano lessons. This was followed by an increase in piano concerts and competitions for piano players. However, in these piano performances, when we enjoy the music, it is not difficult to find that many performers have stalls, fragments or even give up playing halfway because of the psychological emotions of nervousness and stage fright. The reason is that there are some problems in the self-regulation of piano education.

\subsection{VR Technology Helps to Adjust the Mentality of Piano} Players. Before we solve the problem, let us first look for the reasons why the pianist experience nervousness and stage fright during the performance. As is known to all, pianists' daily training is very boring, because the limitations of the piano's own conditions, the daily training of the players cannot be carried out outdoors. And, often, it can only be performed alone in a closed space such as a home or piano room, so the performer generally lacks practical experience. Once in actual combat, facing so many audiences, you will unconsciously feel nervous, nonconfident, and irritable. For those players who lack self-confidence and psychological adjustment ability, once such negative emotions appear, and it will greatly affect the normal performance of their competition results.

The adjustment of mentality does not depend entirely on the subjective initiative of the performer. VR technology can build a virtual piano performance stage so that the performer can personally feel the feeling of the live performance, so as to strengthen the psychological adaptability training and reduce the misalignment problems caused by nervousness and stage fright during the performance. VR technology helps to adjust the realization method and process of the piano player's mentality and the effect after realization. This paper will make specific introduction and analysis in the third and fourth parts.

\section{Construction of Virtual-Reality Piano Performance Stage Based on VR Technology}

Pianists often suffer from jams and interruptions during performance due to limitations of their own personality or 
objective conditions, lack of live performance experience, and the ability to effectively regulate psychological pressure. This paper attempts to use VR technology to build virtual reality stage for playing the piano, lets players in the process of daily piano training experience the feeling of live performance, fully improve the war experience, and through simulating the onsite stage environment, the mental quality training of the performers is strengthened.

\subsection{Modeling Method of Virtual Piano Performance Stage.} Before modeling, we should first clarify the modeling method to be used, which is a key step in the realization of virtual reality technology and make the stage of the virtual representation look realistic with real movement, real sound, and real sense. We need to choose the most appropriate modeling methods and modeling tools to achieve this to make the virtual stage more realistic and be used in practice in life. In this modeling experiment, 3DsMax9 modeling tool was selected. According to the different characteristics of different objects on the piano stage, including the audience, the following two modeling methods were mainly adopted.

(1) Geometric Modeling: The geometric modeling method is to directly use geometric polygons in 3DsMax9 to create a model. Describe the shape and characteristics of the piano performance stage. Build a basic model through a simple distortion processing function and create a simulation for players to practice. For more regular entities such as the stage, piano, auditorium seats, and hall lighting in the performance scene, geometric modeling can be directly carried out through 3DsMax9. For irregular entities, one or more geometric entities are used for mixed modeling. During modeling, these irregular entities are determined by polygons, triangles, or vertices, and the solid surfaces are determined by surface textures, lighting coefficients, colors, etc.

The specific steps are as follows:

First, select geometry items in the 3DsMax9 creation panel to create a rectangular model, and then enter the Modify panel to convert the model into editable polygon.

Secondly, adjust and modify points, lines, and surfaces; add transversal segments of polygons; and perform mesh smoothing operation on polygons in the modification panel when necessary, so as to continuously refine the model and produce the basic model.

Third, make materials and maps by using the acquired basic data and pictures of the stage environment of piano playing, carry out texture mapping and map baking, and complete the model construction.

(2) Image Modeling: Image modeling is the reconstruction of three-dimensional model by using image and video data, which is suitable for the modeling of human body structure in the auditorium under the stage. The specific steps are as follows:
First, use digital camera or laser scanning microscope to shoot and scan objects which are close or far away. Use a digital camera to cross the front, back, left, and right four directions of the object. Objects in different directions are shot at the same height. With a laser scanning microscope, you simply aim at the object and perform a full sweep.

Second, since the object image acquired is not only the audience, the image needs to be matted. Delete the rest of the image matting, only retain the viewer's body structure area, and save the diffuse color map and opaque map.

Third, enter the material editor of 3DsMax9, import the prepared human image specimen map into it, align the front, back, left, and right maps, and then create a cross face, prepare the material and edit for it, and produce a three-dimensional human body structure specimen model based on the human image.

3.2. Construction of Virtual Piano Performance Stage. The virtual scene of the piano performance stage is a digital scene sketched by the computer system using its digital communication technology. The construction of the virtual scene model mainly includes the stage layout and the layout of the audience, which can satisfy the online roaming and interactive experience of people in the real world. After all the single models are built, they need to be placed and assembled to create a real virtual reality environment and reproduce the real world. Specific implementation methods are as follows.

3.2.1. Acquisition of 3D Data of Realistic Piano Performance Stage. Any model must rely on physical 3D data to create a 3D virtual piano to obtain 3D data of the real stage, including concert hall architecture data. Decoration design information and onsite survey data, include concert hall construction data, decoration design information and site survey data, concert venue design, number of people and specific sound effects in various locations, as well as multiangle photos of human bodies in real scenes. After data collection, statistical analysis software SPSS22.0 was used for data preprocessing, and the statistical formulas involved were as follows.

Geometric mean:

$$
G=\sqrt{x_{1} \times x_{2} \times \ldots \times x_{n}}=\sqrt{\prod_{i=1}^{n} x_{i}} .
$$

Harmonic mean:

$$
H=\frac{m_{1}+m_{2}+\ldots+m_{n}}{\left(m_{1} / x_{1}\right)+\left(m_{2} / x_{2}\right)+\ldots\left(m_{n} / x_{n}\right)}=\frac{\sum_{i=1}^{n} m_{i}}{\sum_{i=1}^{n}\left(m_{i} / x_{i}\right)} .
$$

The specific model is expressed as follows:

$$
X_{f_{1}}(t)=\sum_{k=1}^{K} \sum_{f \in D_{k}} S_{f} V_{k}+A_{f} \sin \left(\pi f t+\phi_{f}\right) .
$$


$X_{f_{1}}(t)$ represents the sound of the electronic pipe.

$$
Q=\bigcup_{k}^{K} Q_{k}=Q_{1} \cup Q_{2} \cup \ldots \cup Q_{k} \cup \ldots \cup D_{K} .
$$

During the performance, the performer will adjust the amount of pedal use immediately according to the feedback. Variable frequency range of section $k$ :

$$
F_{k}-\partial F_{1} \leq T_{k} \leq F_{k}+\partial F_{1}
$$

Among them, $F_{1}$ is the pitch frequency:

$$
F_{k}=T F_{1}(T=1,2,3, \ldots, t)
$$

\subsubsection{D Modeling of Virtual Scene of Piano Performance}

Stage. Step 1. Make a model: In order to obtain the real 3D data information of the piano stage, we have actually considered the actual stage building structure, the stage environment and the number of spectators in the auditorium, and set up the virtual piano using 3DsMax9 geometric polygons. On the basis of modeling, the basic model is modified and adjusted through the $3 \mathrm{ds}$ Max 9 modification editor to make it conform to the basic environment of the stage virtual reality piano performance stage, whil. For the audience, camera sampling is adopted and image modeling is used.

Step 2. Make the material: After the basic model is built, the material editor needs to be used to make the material, which mainly includes the texture map of the piano performance stage, such as diffuse reflection, specular light, environmental reflection, reflection refraction, and other specular parameter settings, because the texture of each model is different. Consistent UVW texture mapping must be performed according to different polygon models. UVW is a texture modifier. After taking a picture and sampling the playing scene, the image must be processed by Photoshop into a virtual piano scene map and finally it is paired with geometric patterns through the surface.

Step 3. Set up lights and cameras: In the real piano performance stage, its lighting effect is essential, so in order to highlight the authenticity of the virtual stage, we also need to add lighting and camera elements here. Lighting determines the tone and feeling of the virtual scene, setting off the scene atmosphere. The virtual stage lighting setup here adopts the target spotlights, free spotlights, and floodlights in3Ds Max9. The added camera is equivalent to the user's eyes. It simulates the way of observing the model in the virtual three-dimensional space and gives the player the feeling of playing live.

Step 4. Render and texture baking: After the above steps are completed, the virtual stage shall be rendered with color and environment to make it more similar to the real stage and achieve a realistic effect. Here, we use texture mapping technology to transform the light information into texture mapping, which greatly improves the computing efficiency.

Step 5. Optimize the model: After the final model is built, the model needs to be checked and optimized to reduce the complexity of the virtual stage scene and improve the real-time interaction speed and efficiency of the system.

\subsubsection{Synthesis of Virtual Scene Model of Piano Performance} Stage. After the basic model, human structure specimens and materials are built, and the last step is to put all the individual models back and set, and finally form a complete three-dimensional virtual piano performance stage. After that, interactive behaviors are added to make it responsive and interactive with users, so that players can truly feel the feeling of live performance and experience the charm of virtual reality.

\section{Analysis of the Auxiliary Effect of VR Technology on the Adjustment of Piano Playing Mentality}

In the third part of this article, we use VR technology to construct a virtual reality piano stage and create a realistic $3 \mathrm{D}$ virtual piano performance stage. This virtual piano performance stage creates a real live performance effect for pianists to the greatest extent, which can help players exercise their mental quality, improve their resilience to live performance, and reduce their nervousness, stage fright, anxiety and other bad emotions during their performance.

In order to further explore the impact of VR technology on the psychological adjustment of players during piano performance, 20 young piano learners are now selected to participate in the investigation and experiment, using VR technology to build a virtual piano performance stage. 20 young piano learners were randomly divided into test group and control group, two groups of every 10 people, including test group 4 boys and girls 6 people; average age was $14.2 \pm 2.3$ years of age, piano learning time was $4.5 \pm 1.44$ years. In the control group, there were 7 boys and 3 girls, with an average age of $15.7 \pm 2.5$ years and a piano learning time of $5.1 \pm 2.34$ years. The test group received daily piano training on the virtual reality piano performance stage, while the control group received ordinary daily piano training in the piano room. The training time was three months, and the training time was 4 hours every day. After three months, these 20 piano learners would participate in the Provincial Youth Piano Competition. The basic information of the two groups of piano learners is shown in Table 1, and the stage model of virtual reality piano performance is shown in Figure 1 .

4.1. Comparison of Performance Level between the Two Groups of Subjects in the Piano Competition. The two groups of subjects received daily training in different piano practices for three months. After that, we recorded the performance 


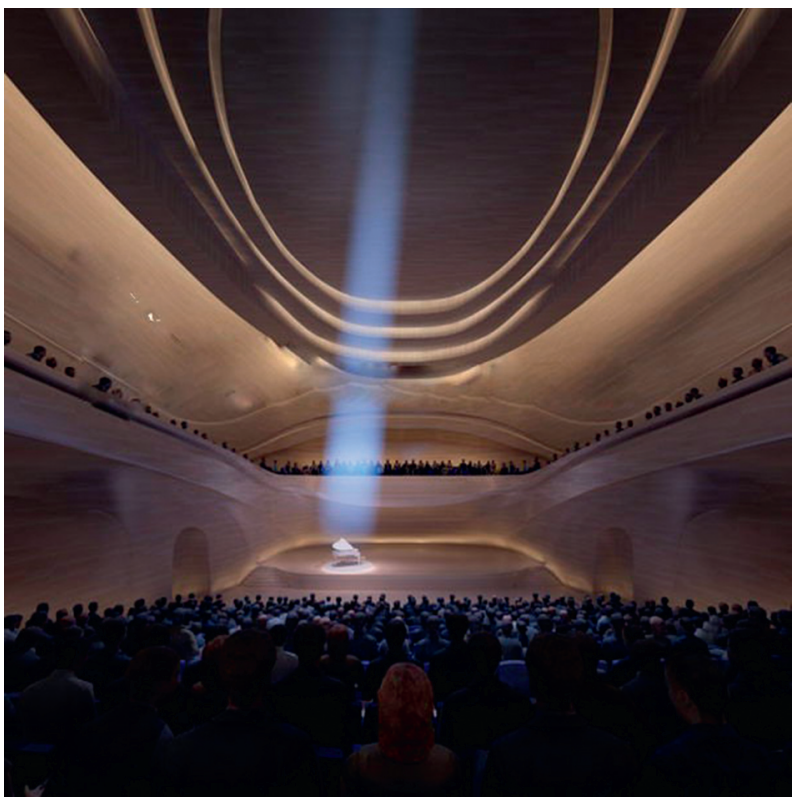

FIGURE 1: 3D virtual reality piano playing stage model.

TABLE 1: Basic situation of piano learners.

\begin{tabular}{|c|c|c|c|c|}
\hline \multirow{2}{*}{ Group } & \multicolumn{2}{|c|}{ Gender } & \multirow{2}{*}{ The average age of } & \multirow{2}{*}{ The average time of learning the pianc } \\
\hline & Man & Woman & & \\
\hline Test group & 4 & 6 & $14.2 \pm 2.3$ & $4.5 \pm 1.44$ \\
\hline Control group & 7 & 3 & $15.7 \pm 2.5$ & $5.1 \pm 2.34$ \\
\hline
\end{tabular}

and performance of the two groups of subjects at the piano competition. The specific conditions investigated are shown in Table 2 and Figure 2.

As shown in Table 3 and Figure 2, the subjects in the test group performed significantly better than those in the control group in this piano competition. Two of them performed particularly well and achieved excellent performance. There were 7 players who were very relaxed and played at a normal level in the competition. The other player was a little nervous during the performance and had a slight jamming phenomenon, but he finished the performance successfully. In contrast, only 3 of the 10 subjects in the control group performed normally. 4 were a little nervous, slightly stuck. However, two players were very nervous during the competition. They got stuck in the performance for many times and broke pieces. Even one player stopped playing and gave up the game due to emotional loss. Pianists in the big games, therefore, adjusting the mentality and controlling the mood is very important; bad state of mind will severely hamper the normal level of play to players. The average age of the 10 players in the control group of is bigger than the test group, and the piano study time is longer than that of the control group, but after the test groups trained in the environment of the $3 \mathrm{D}$ virtual play stage for three months, the overall psychological state and mentality in the self-adjusting ability was significantly higher than the control group subjects, the technical level of piano performance is also significantly higher than that of the test group. However, due to the neglect of the reinforcement training of psychological adaptability in the daily training, the competition in front of so many people will easily produce nervousness, low self-confidence, and stage fright, which greatly affects the performance of their normal level. In this regard, it can also be seen that the $3 \mathrm{D}$ virtual reality piano performance stage constructed by VR technology plays a very auxiliary role in the adjustment of players' mentality.

Pure law fifth cycle is show in Table 1. The advantage of this temperament is that it has the largest number of pure intervals, including 23 pure intervals. However, the disadvantage of this temperament is that there are many wolf sounds in fifths, and there is a wolf sound that is wider than 41.1 cents and cannot be used at all. There are also 4 major thirds of wolf sounds; there are four completely different minor thirds, which is too complicated. And because the distribution of pure tones is very scattered, even if there are many pure tones, they cannot be adjusted at will. The only tones that can be adapted are F major, A major, and a minor. The mid-shoulder whole tone is shown in Table 4.

If two tones sound at the same time, then according to the characteristics of the overtone series, in the overtone series of the two tones, two of the overtones will be equal, and the two equal overtones are called common multipliers sound. The temperament of the twelve equal temperament is to artificially increase and decrease the interval distance in the natural law, so that the actual interval frequency changes slightly, which affects the original structure of the interval in the natural law, and the frequency ratio of the twelve equal temperament. It is not much different from the pure 
TABLE 2: The performance of the two groups of subjects at the piano competition.

\begin{tabular}{lccccc}
\hline Group & $\begin{array}{c}\text { Super long } \\
\text { play }\end{array}$ & $\begin{array}{c}\text { Be relaxed and perform } \\
\text { normally }\end{array}$ & $\begin{array}{c}\text { A little nervous, } \\
\text { slightly stuck }\end{array}$ & $\begin{array}{c}\text { Very nervous and the jam } \\
\text { is serious }\end{array}$ & $\begin{array}{c}\text { Stage fright, and stop playing } \\
\text { in the middle }\end{array}$ \\
\hline $\begin{array}{l}\text { Test group } \\
\begin{array}{l}\text { Control } \\
\text { group }\end{array}\end{array}$ & 2 & 7 & 1 & 2 & 1 \\
\hline
\end{tabular}

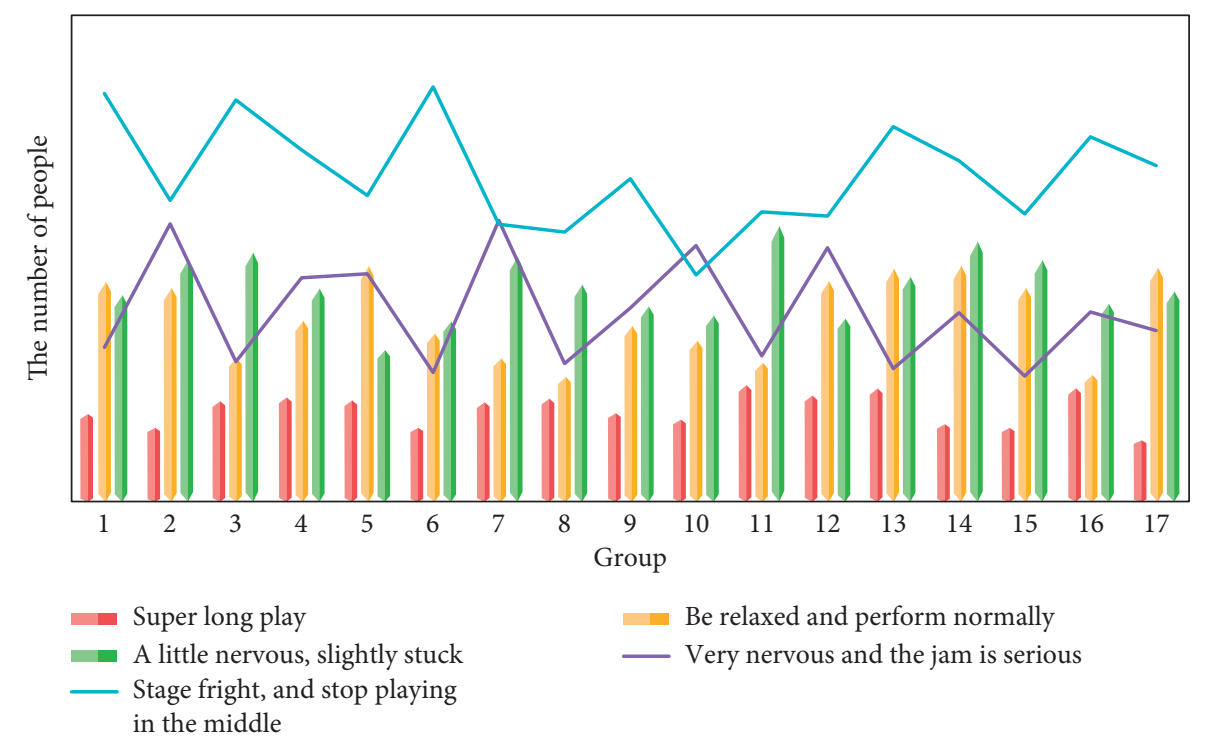

Figure 2: The performance of the two groups of subjects at the piano competition.

Table 3: Pure law fifth cycle.

\begin{tabular}{lcccc}
\hline Temperament & $b e$ & $b b$ & $f$ & $c$ \\
\hline Blunt five degrees & -21.5 & 0 & 0 & 0 \\
Major third & 0 & 0 & 0 & 0 \\
Minor third & -13.8 & 7.71 & 7.71 & 0 \\
\hline
\end{tabular}

TABLE 4: The mid-shoulder whole tone.

\begin{tabular}{lcccc}
\hline Temperament & $b e$ & $b b$ & $f$ & $c$ \\
\hline Blunt five degrees & -5.376 & -5.376 & -5.376 & -5.376 \\
Major third & 0 & 0 & 0 & 0 \\
Minor third & 2.3 & 2.3 & 2.3 & -5376 \\
\hline
\end{tabular}

temperament frequency, but there will still be a certain distance between the co-octave, and the phenomenon of beating will appear. The concordance of intervals is shown in Table 5 .

4.2. Analysis of the Influence of Age on the Mentality of Players. In this experiment to investigate, through horizontal comparison, we also found that age also has a certain impact on the technical level and psychological quality of piano players. Older players have better technical skills and stronger psychological endurance, while younger players have the opposite effect. In the control group, tension, jamming, and splintering also occurred in subjects younger than 17, participants aged 13 discontinued, and three subjects older than 18 performed normally. And the older the
TABLE 5: The concordance of intervals.

\begin{tabular}{lcclcc}
\hline Interval & \multicolumn{2}{c}{ Four degrees } & \multicolumn{2}{c}{$\begin{array}{c}\text { Five } \\
\text { degrees }\end{array}$} \\
\hline Key tone & $32 \mathrm{E}$ & $37 \mathrm{~A}$ & Beating situation & $32 \mathrm{E}$ & $39 \mathrm{~B}$ \\
Pitch frequency & 164.81 & 219.75 & & 164 & 247 \\
\hline
\end{tabular}

subjects were, the longer they had been learning the piano. The field performance comparison of subjects of different ages in the two groups is shown in Figures 3 and 4.

As can be seen from Figures 3 and 4, subjects who are older and have been learning the piano for a longer time actually perform with more stability and better self-adjustment ability when they are trained on the virtual piano stage. The field performance of control subjects trained in the same environment was similar, compared with older subjects who had been learning to play the piano for a long time often performing better. It shows that the age of players has a certain influence on the adjustment of their on-thespot mentality and performance level. Recognition results of chords are shown in Table 6.

4.3. Analysis of the Influence of Gender and Personality on the Mentality of Players. In addition to the age factor, we have also found in our research that differences between men and women and differences in player personality also affect how normal they perform in live performances. In the competition, boys tend to be more stable than girls and did not show any symptoms of discomfort. People who are 


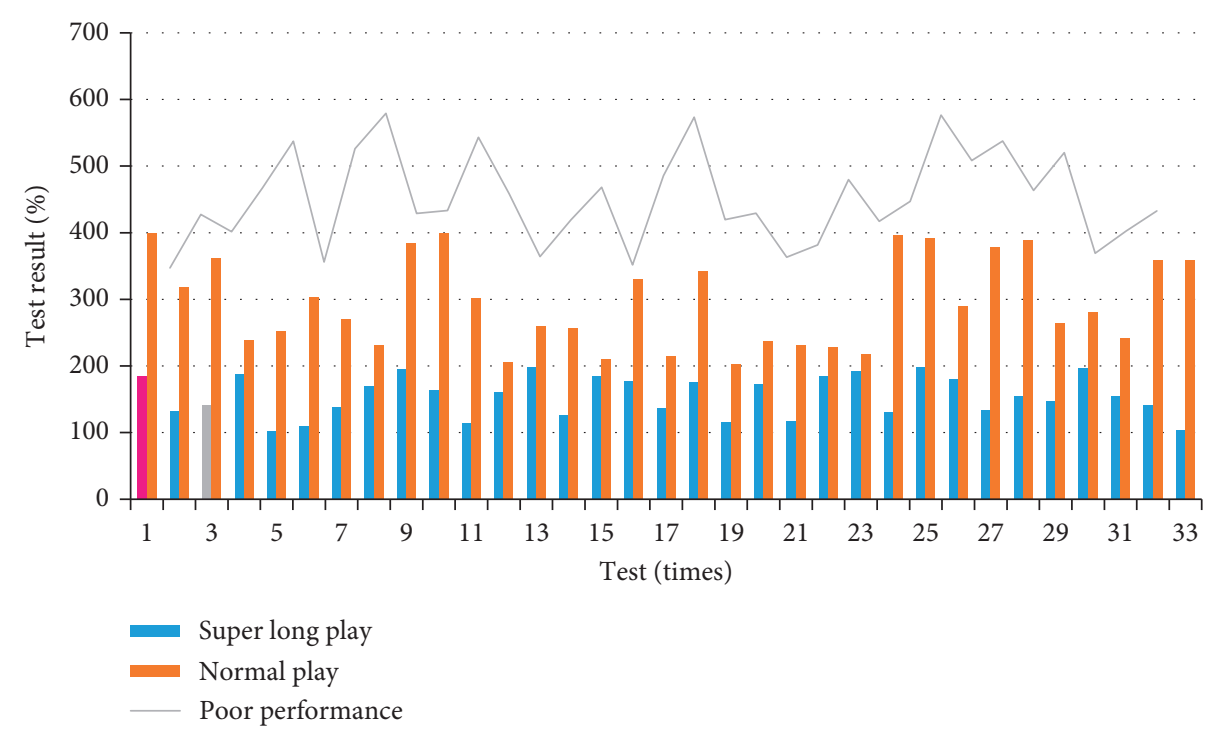

FIGURE 3: Live performance of subjects of different ages in the Test group.

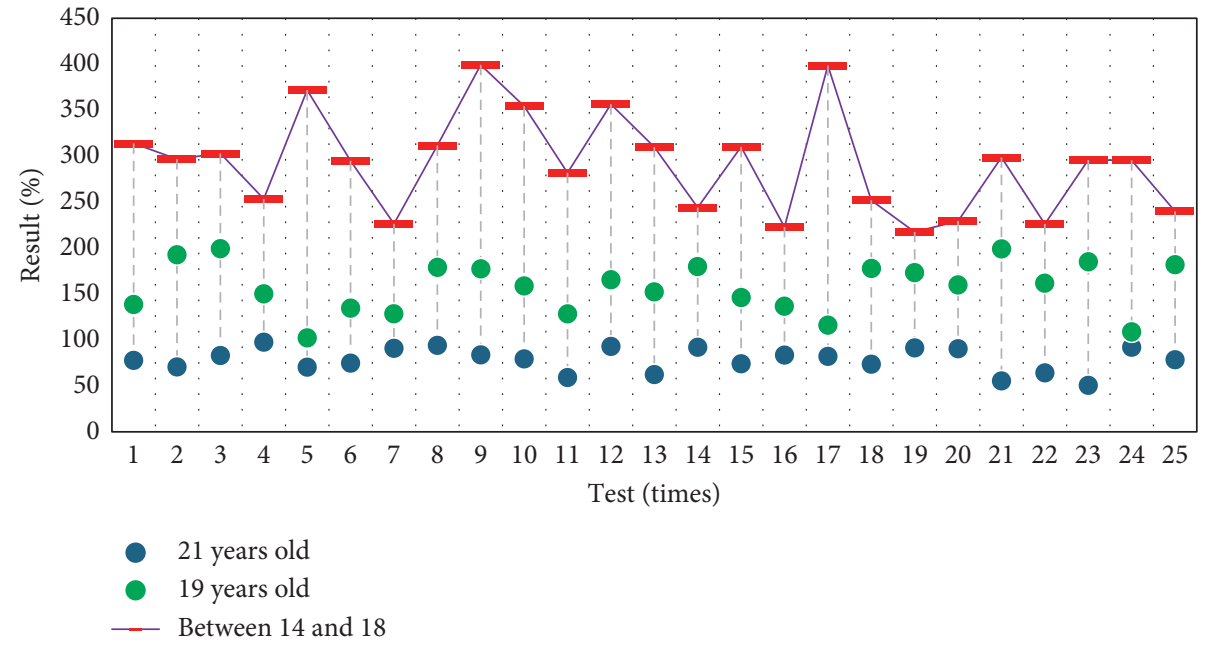

Figure 4: Live performance of subjects of different ages in the control group.

TABLE 6: Recognition results of chords.

\begin{tabular}{lcc}
\hline Test data & Length & Recognition rate (\%) \\
\hline Fragments of piano music & 8 seconds/44 frames & 60 \\
Piano piece & 120 seconds/661 frames & 70 \\
\hline
\end{tabular}

optimistic and strong tend to work better than introverted and insecure people. There were 11 male and 9 female subjects in the two groups. According to the investigation, there were 4 outgoing boys and 3 outgoing girls. There were 5 boys and 4 girls with lively and optimistic personality. There are two boys and two girls who are introverted and lack confidence. The specific situation is shown in Figure 5.

As can be seen from Figure 5, male students generally performed better than female students in the competition. Among the 11 male students, 3 had excellent performance, 5 had good performance, 2 had average performance, and only 1 had poor performance. Of the 9 girls, 2 were excellent, 3 were good, 2 were average, and 1 was poor. And the players who perform well are optimistic and confident, while those who do not are introverted and lack confidence. This shows that the differences of players' personalities will also affect their performance in competitions. Boys generally have better psychological endurance and stress tolerance than girls, so they tend to perform better in terms of psychological self-regulation during competitions. Relevant frequencies used when extracting base collar is show in Table 7.

In order to have a more comprehensive understanding of the performers' psychological changes on stage and the specific manifestations of various unhealthy psychological states, a questionnaire survey (see appendix) has been conducted on the psychological state of 60 surveyed piano 


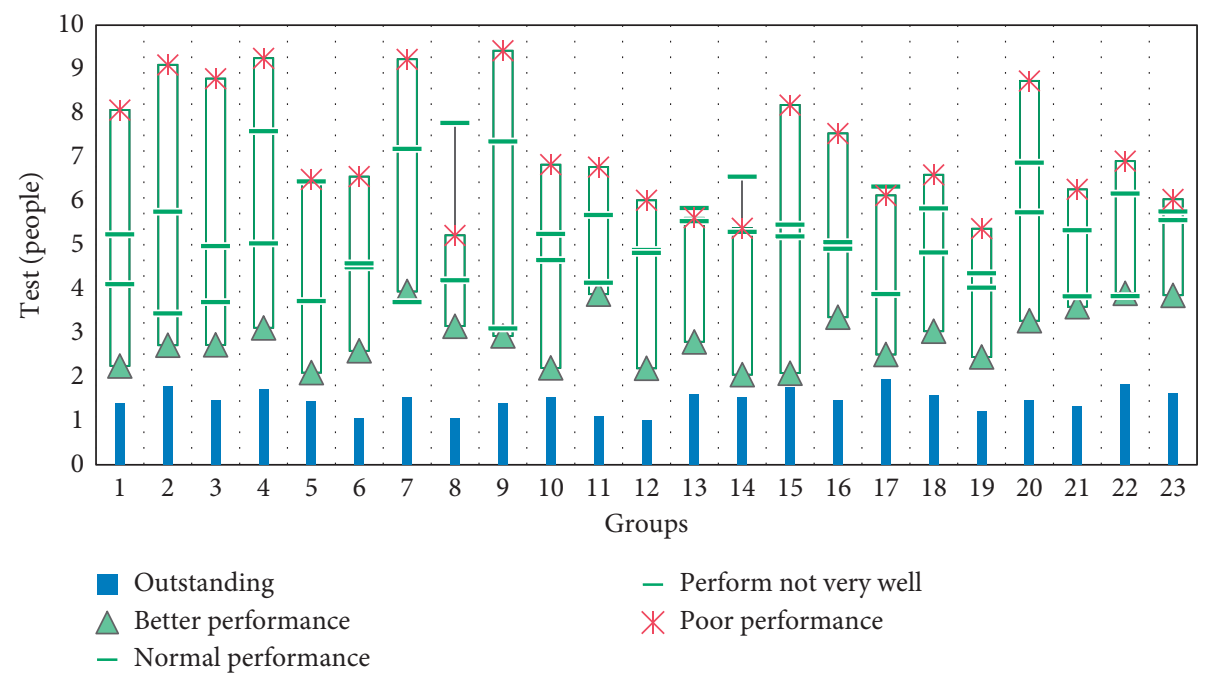

FIGURE 5: The influence of personality and gender on performers' live performance.

TABle 7: Relevant frequencies used when extracting base collar.

\begin{tabular}{lccc}
\hline Musical alphabet & Calculated frequency $(\mathrm{Hz})$ & Normalized stop frequency $(\mathrm{Hz})$ & Program \\
\hline \#a & 330 & 335 & 330 \\
t1 & 362.63 & 369 & 363 \\
f1 & 322.23 & 329 & 322 \\
g1 & 349.33 & 359 & 349 \\
\hline
\end{tabular}

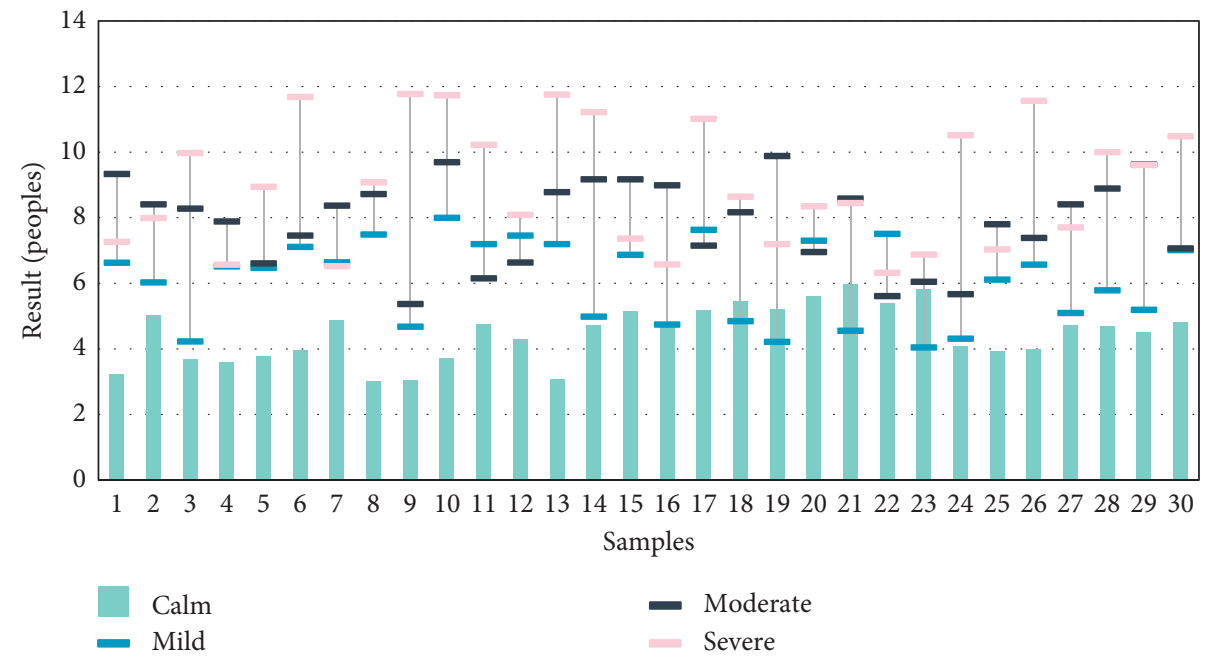

FIgURE 6: The survey results.

subjects before, during, and after the performance. In addition, in order to initially explore whether there are differences between male and female groups, this survey ratio of male to female is $1: 1$. The survey results are shown in Figure 6.

According to the survey results, $7 \%$ of the respondents did not experience physical discomfort, and another $93 \%$ of the respondents reported a series of physical discomforts. It can be seen that the physical performance of the bad mental state of the performers accounted for a considerable proportion. This mainly includes changes in heartbeat and breathing rate, gastrointestinal disorders, headaches, dizziness, weakness of the limbs, muscle stiffness throughout the body, shaking hands and knees, unconscious lip licking, cold hands and feet, etc. The discomfort in the piano performance is shown in Figure 7.

It can be seen from the survey data that only $10 \%$ of the respondents can always devote themselves to their own music, $23 \%$ of the investigators are always unable to, and $67 \%$ of the investigators are in an unstable state of performance, which includes negative emotions, unstable mentality, loss of confidence, inability to concentrate, fear of 


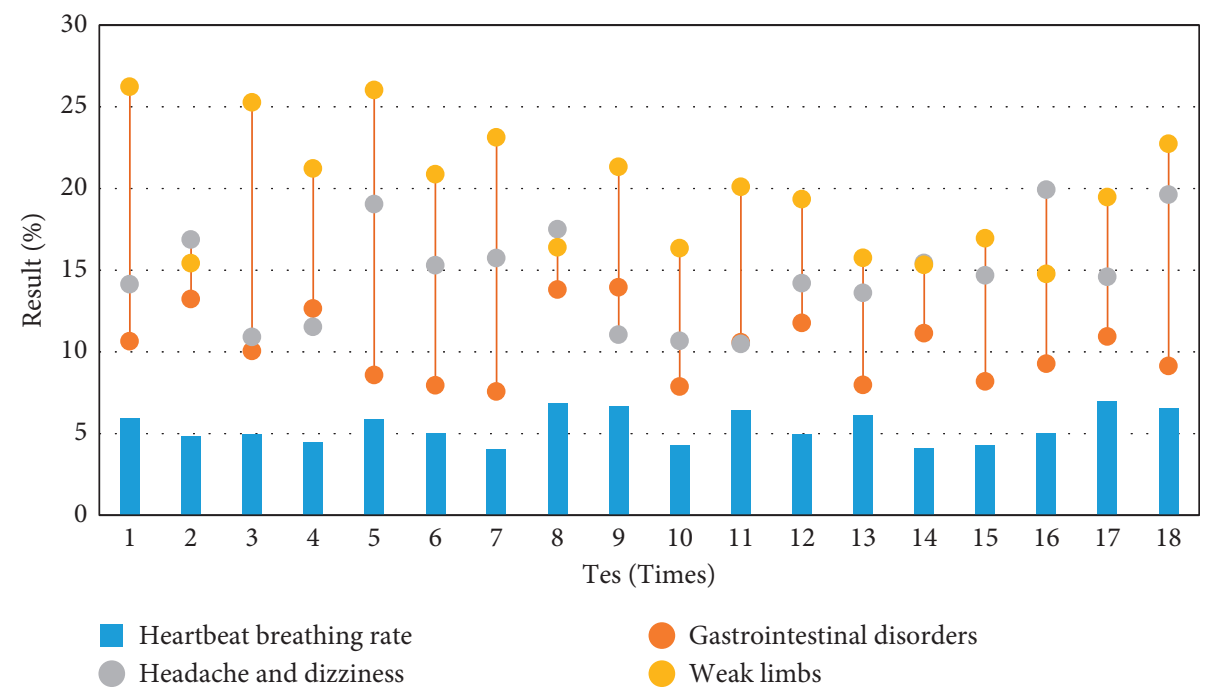

Figure 7: The discomfort in the piano performance.

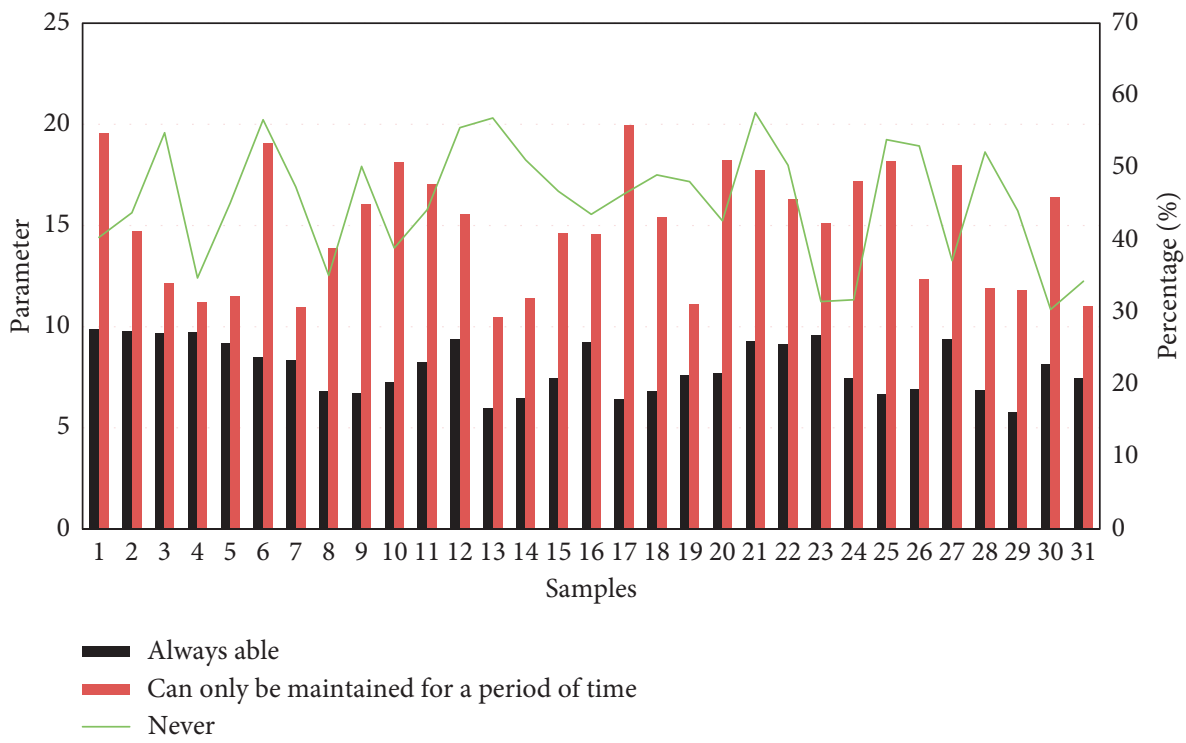

Figure 8: The results of the survey that can be fully focused during performance.

making mistakes, expectation of super-level performance, and irritability. Figure 8 shows the results of the investigation where the attention can be fully concentrated during the performance.

\section{Conclusions}

Piano performance is a kind of elegant artistic performance, but also a complex psychological process. Players should not only get used to perform to their vision, hearing, touch, and other sensory organs, but also their thoughts, feelings, mind, and attention, such as internal, complicated, comprehensive psychological activity, players coordination, their motion perception, and consciousness as well the relations of various kinds of psychological factors.

For a long time, many piano students and even some excellent piano players often fail to perform properly due to their mental problems on the spot. How to overcome this nervousness and stage fright and improve the ability of selfadjustment during live performance is an urgent problem that every piano player wants to solve. For this reason, this paper proposes to apply VR technology to piano performance. By establishing the stage model of $3 \mathrm{D}$ virtual reality piano performance, the players can experience the feeling of live performance in their daily training and strengthen their psychological adaptability training, so as to improve their self-regulation ability of on-the-spot mentality.

In this study, through the investigation and test of 20 young piano learners, it is found that the subjects who receive daily training in the $3 \mathrm{D}$ virtual piano performance stage environment have much better mental self-regulation ability and live performance level in actual practice than those who receive training in the ordinary environment. The study also found that gender, age, and personality had an 
impact on players' minds. When players have a good idea, expressive music will make people happy and vice versa. In short, the use of VR technology to build a three-dimensional virtual piano performance stage model can help players strengthen psychological adaptability training to a certain extent and assist in adjusting their mentality during performance, and its application effects have been verified, which will be a trend in the future.

\section{Data Availability}

The data that support the findings of this study are available from the corresponding author upon reasonable request.

\section{Conflicts of Interest}

The author(s) declare no potential conflicts of interest.

\section{References}

[1] T. Tian, "Discussion on the role of psychological regulation of in piano performance," Journal of Heihe University, vol. 9, no. 1, pp. 186-187, 2018.

[2] H.-x. Bian, "Application of virtual reality in music teaching system," International Journal of Emerging Technologies in Learning (iJET), vol. 11, no. 11, p. 21, 2016.

[3] L. Chen, "An optimization analysis of modern piano playing mode based on ultimedia system," Boletin Tecnico/technical Bulletin, vol. 55, no. 11, pp. 519-525, 2017.

[4] Z. Zhou, "Application of timbres of national musical instruments in the performance of Chinese piano works," International Technology Management, no. 12, pp. 83-84, 2016.

[5] Z. Lv, X. Li, and W. Li, "Virtual reality geographical interactive scene semantics research for immersive geography learning," Neurocomputing, vol. 254, pp. 71-78, 2017.

[6] T. Li, L. Ming, R. Wang et al., "Comment on the application of VR technology in ideological and political theory teaching," Journal of Shenyang Institute of Education, vol. 21, no. 4, pp. 475-478, 2019.

[7] G. Messalli, A. Palumbo, E. Maffei et al., "Valutazione volumetrica del ventricolo sinistro mediante cardio-RM: confronto tra due software quantitativi semi-automatici," $L a$ Radiologia Medica, vol. 114, no. 5, pp. 718-727, 2016.

[8] N. W. Blo, L. Lindkvist, and D. Hjorth, "Organizing cultural projects through legitimising as cultural entrepreneurship," International Journal of Managing Projects in Business, vol. 8, no. 4, pp. 696-714, 2016.

[9] J. L. V. Yusbiel, B. S. O. Reinaldo, E. G. Silvera et al., "Behavior of predictive variables of exacerbations of the COPD in the neumological hospital of Cuba," Revista De La Facultad De Ciencias Medicas, vol. 74, no. 2, p. 93, 2017.

[10] A. Zabardasti, N. Talebi, A. Kakanejadifard, and Z. Saki, "The $\mathrm{B}-\mathrm{C}$ and $\mathrm{C}-\mathrm{C}$ bonds as preferred electron source for $\mathrm{H}$-bond and Li-bond interactions in complex pairing of C4B2H6 with $\mathrm{HF}$ and LiH molecules," Structural Chemistry, vol. 27, no. 2, pp. 573-581, 2016.

[11] Z. Lv, X. Li, H. Lv, and W. Xiu, "BIM big data storage in WebVRGIS," IEEE Transactions on Industrial Informatics, vol. 16, no. 4, pp. 2566-2573, 2019.

[12] Y. Dai, "Research on the application of VR technology in the local resources of high school history," Scientific Education Magazine, vol. 334, no. 4, pp. 138-159, 2018.
[13] Q. Liu, L. Yang, Z. Xiao et al., “Application of VR technology in the treatment of depression," Science Education Journal, no. 8, pp. 60-61, 2019.

[14] H. Wang, "Application of VR technology in college golf teaching\% VR technology in college golf teaching," Journal of Qiqihar Teachers College, no. 5, pp. 112-114, 2018.

[15] Y. Lu, "The application of VR technology in the laboratory of colleges," Office Automation (Office Equipment and Consumables), vol. 23, no. 4, pp. 47-48, 2018.

[16] X. Wang, "SWOT analysis of the application of VR technology in the production and safety construction of the port and wharf," Value Engineering, vol. 35, no. 29, pp. 33-35, 2016.

[17] R. Luo, "Performance analysis and application of anti interference technology in wireless communication," Mobile Information, no. 6, pp. 110-112, 2016.

[18] H. J. S. Birch and E. Woodruff, "Technical exercise practice: can piano students be motivated through gamification?" Journal of Music, Technology and Education, vol. 10, no. 1, pp. 31-50, 2017.

[19] E. C. Schoenmakers, J. Damron-Rodriguez, J. C. Frank, B. Pianosi, and J. S. Jukema, "Competencies in European gerontological higher education. An explorative study on core elements," Gerontology \& Geriatrics Education, vol. 38, no. 1, pp. 5-16, 2017.

[20] M. Flückiger, T. Grosshauser, and G. Tröster, "Influence of piano key vibration level on players' perception and performance in piano playing," Applied Sciences, vol. 8, no. 12, p. 2697, 2018.

[21] R. Chen, "Memorization of piano music: a challenge for Chinese piano students," Asian Social Science, vol. 12, no. 3, p. 112, 2016.

[22] L. Laor, "In music nothing is worse than playing wrong notes," Journal of Historical Research in Music Education, vol. 38, no. 1, pp. 5-24, 2016.

[23] S. Kim and C.-Y. Kim, "Playing visual dominance of score on the piano: skilled motor action matters in the awareness of musical notes during binocular rivalry, only when accompanied by auditory feedback," Journal of Vision, vol. 16, no. 12, p. 1207, 2016.

[24] A. H.-W. Wong, M. Gang, D. Szyld, and H. Mahoney, "Making an "attitude adjustment"," Simulation in Healthcare: The Journal of the Society for Simulation in Healthcare vol. 11, no. 2, pp. 117-125, 2016.

[25] L. Zhang, "Problems and countermeasures of piano teaching in normal universities," Educational Theory and Practice, vol. 36, no. 30, pp. 63-64, 2016.

[26] Li Ning, "The artistic expression of piano accompaniment to art songs," Journal of Jiamusi Education College, no. 8, pp. 318-320, 2018. 